\title{
Utilizing the Internet to Promote Health Behaviour Changes Among Rural-Living Young Adult Cancer Survivors
}

Jenson Price ${ }^{1}$, Jennifer Brunet 1,2,3

${ }^{1}$ Department of Human Kinetics, University of Ottawa, Ottawa, Ontario, Canada

${ }^{2}$ Institut du Savoir de l'Hôpital Montfort (ISM), Montfort Hospital, Ottawa, Ontario, Canada

${ }^{3}$ Ottawa Hospital Research Institute (OHRI), Ottawa, Ontario, Canada

ABSTRACT

Regular physical activity (PA) participation and fruit and vegetable (FV) consumption confer numerous health benefits for cancer survivors. Rural-living young adult cancer survivors report barriers to participation in health-promoting behaviours such as the lack of physicians/specialists, limited PA programming, lack of affordable FVs, and unreliable transportation to/from PA facilities. Interventions seeking to promote PA participation and FV consumption fail to address many barriers rural-living young adult cancer survivors have because they are traditionally offered in urban centres. Alternative means for delivering PA and FV consumption behaviour change interventions need to be developed, implemented, and evaluated for this population.

\section{RÉSUMÉ}

L'activité physique régulière et la consommation de fruits et légumes apportent de nombreux avantages pour la santé des survivants du cancer. Les jeunes survivants du cancer qui habitent en milieu rural soulignent des obstacles à l'adoption de comportements favorables à la santé, tels que le manque de médecins/spécialistes, le nombre limité de programmes d'activité physique, le manque de fruits et légumes abordables et le transport peu fiable vers/depuis les installations d'activité physique. Les interventions visant à promouvoir l'activité physique et la consommation de fruits et légumes ne parviennent pas à répondre aux nombreux obstacles rencontrés par les jeunes adultes survivants du cancer qui habitent en milieu rural car elles sont traditionnellement offertes dans les centres urbains. Des moyens alternatifs pour réaliser des interventions de changement de comportement en incitant l'activité physique et la consommation de fruits et légumes doivent être développés, mis en œuvre et évalués pour cette population.

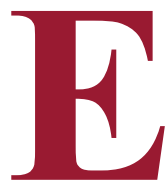
ach year, approximately 1 million young adults between the ages of 20-39 years are diagnosed with cancer worldwide [1]. On average, $80 \%$ of young adults will survive 5 years or more after diagnosis [1]. Physical activity (PA) participation and fruit and vegetable (FV) consumption can prolong life expectancy [2, 3]. Additionally, PA participation and FV consumption can prevent or delay various cancer-related physical and psychosocial side effects and promote overall health $[4,5]$. For example, PA can improve aerobic capacity, elevate energy levels, and enhance body composition [6], and, FV consumption can promote physical, psychological, and social health [7-9].

Drawing on cumulative evidence, PA participation and FV consumption guidelines have been developed. For PA participation, guidelines recommend that cancer survivors participate in at least 150 minutes of aerobic training at moderate-to-vigorous intensity each week and strength training twice per week. For FV consumption, guidelines recommend that cancer survivors consume at least five servings of FVs each day. Despite guidelines being widely distributed to the public by various organizations (e.g., Canadian Cancer Society, American College of Sports Medicine; [10, 11]), compliance with both is low [12]. To improve compliance with guidelines, various interventions targeting cancer survivors have been developed. However, there are concerns that most existing interventions may not reach all cancer survivors because they are often delivered by research staff in hospitals or at research facilities located primarily in urban centres [1315].

\section{RURAL-LIVING YOUNG ADULT CANCER SURVIVOR}

There are many health disparities associated with living in a rural community [14]. Individuals living in rural communities report poorer overall health outcomes than their urban counterparts [15-17]. Across developed and underdeveloped nations, data on geographical location point to an increase in cancer-related morbidity and mortality for those living in rural communities [18], which may, in part, be due to lower PA participation [19] and FV consumption [20]. For FV consumption, rural residents experience greater economic burden, increased spatial distance, lower quality, and

Keywords: Rural; Health; Behaviour change; Cancer survivors; Young adults; Telehealth 
limited availability of FVs [21-24]. For PA, participation in rural communities is hindered by the built environment (e.g., limited parks, sidewalks, and streetlights), long distances to recreational athletic centres, lack of transportation to/from PA facilities, and poor walkability (e.g., high speed limits, winding roads), and minimal variety for PA types $[25,26]$.

In addition to the above-mentioned constraints associated with living in a rural community, young adult cancer survivors have unique needs compared to those diagnosed as children or later in life [27]. Young adult cancer survivors not only have to manage the adverse cognitive, physical, and psychosocial sequalae associated with a cancer diagnosis and subsequent treatment (e.g., anxiety, depression, physical decondition, fatigue) $[28,29]$, but they must navigate a period in their life that is laden with developmental milestones (e.g., gaining independence, establishing romantic relationships) [30]. They also face a myriad of barriers for participating in healthpromoting behaviours including competing life responsibilities (e.g., work, children), lacking necessary transportation, having limited guidance from health professionals, and experiencing changes in social support (e.g., transitioning from parental support to independence and/or changes in romantic relationships) [31]. At the same time, young adult cancer survivors report a lack of resources, negative thoughts and feelings, and negative social and environmental influences as barriers specific to PA participation and FV consumption [32]. As a result, many young adult cancer survivors decrease their PA participation at diagnosis and fail to regain PA levels post-diagnosis [33]. FV consumption also remains low postdiagnosis [34].

There is a critical need to develop tailored interventions that adequately address the limited access to and availability of healthcare resources and facilities that reduce lifestyle risks for those living with a chronic illness in rural areas [14]. Using different technologies (e.g., Internet, phone) to deliver interventions is a means of addressing access barriers reported by rural-living young adult cancer survivors. For instance, telephone counselling, websites, online support groups, and mobile applications have been developed for and tested with young adult cancer survivors to ease access to health services $[35,36]$. However, such methods used to deliver interventions are not always preferred as they limit interaction between facilitators and participants [37]. Indeed, results of a recent systematic review of health interventions for cancer survivors found that email communications between cancer survivors and service providers (e.g., oncologists, counsellors) are impersonal [37]. This suggests that cancer survivors may prefer and benefit from interventions that incorporate on-going support and interaction with a facilitator. A Gray and colleagues [20] study, in which a 1-year, iteratively-tailored, theory-based behavioural intervention focused on promoting moderate-tovigorous intensity PA, strength training, and proper nutrition among older, overweight, long-term cancer survivors was implemented, provides support for this contention. The intervention was delivered using mailed print materials, telephone prompts, and stepped telephone counseling. The authors observed modest increases in PA participation and FV consumption for rural participants; therefore, distance-based modes of delivery, coupled with support may be feasible and effective among rural-living cancer survivors. Further, young adult cancer survivors have reported distance-based interventions utilizing the Internet as a favourable means of receiving health-promoting behavioural information [38].

\section{TELEHEALTH INTERVENTIONS}

Telehealth is the use of telecommunication (e.g., Internet, phone) and information technology to deliver health assessments, interventions, and/or additional health services from a distance [39]. Telehealth interventions promoting the adoption and maintenance of health-promoting behaviours are increasing in popularity because of the growing need to reach rural-living individuals [40], as they offer a means of facilitating participants' knowledge, skills, and motivation to change their lifestyle behaviours [41]. For individuals unable to travel to urban centres, telehealth interventions provide similar quality of patient care and produce the same outcomes as compared to face-to-face interventions [42]. For this reason, telehealth interventions can increase rural-living young adult cancer survivors' access to care by reducing hospital and travel costs [42].

There is mounting evidence that telehealth interventions can have positive effects on health behaviour in a variety of populations. For instance, based on a review of 34 studies, Davies and colleagues [43] concluded that tailored telehealth interventions that provide educational material on behaviour change are effective in increasing PA participation in a variety of populations (e.g., general population, adults who have diabetes, are overweight, or have mental illnesses). Further, there is evidence to suggest that interventions combining the use of multiple behaviour change techniques (e.g., stress 
management, goal setting, motivational interviewing) may lead to greater changes in the desired health behaviours than interventions only using one behaviour change technique [44, 45]. Importantly, telehealth behaviour change interventions may also address the access barriers that rural-living young adult cancer survivors report for PA participation and FV consumption, but this has yet to be confirmed. As such, it is necessary to establish the feasibility and acceptability of telehealth behaviour change interventions for ruralliving young adult cancer survivors before continuing their implementation and before undertaking efforts to scale them up.

\section{KEY CONSIDERATIONS}

Despite the potential associated with the mode of delivery of telehealth interventions, the limited guiding literature on this style of intervention means it is necessary to conduct research to develop and evaluate feasibility and acceptability before implementing telehealth interventions in large-scale studies or supportive care services. When undertaking such research, it is essential to consider the following.

\section{Develop tailored interventions}

For young adult cancer survivors, the burden of research methods, design issues (e.g., multiple data points, time commitment), and limited access to recruitment are potential barriers to participation in research trials [46]. In addition, ruralliving and young adult cancer survivors report unique barriers and facilitators that influence their participation in healthpromoting behaviours $[47,48]$. To encourage recruitment and adherence to a health-promoting intervention, it would be necessary to tailor study design and intervention components (e.g., materials) to address the specific needs and preferences (e.g., flexible scheduling) of this population. Pugh and colleagues [38] have suggested key factors and preferences that may influence young adult cancer survivors engagement in lifestyle interventions. Specifically, they suggest it may be beneficial for interventions to provide guidance, recognition of individual needs, and social support in addition to ensuring ease of access to the intervention [38].

\section{Use robust study designs}

Few attempts have been made to assess the feasibility of using different modes of delivery for health behaviour change interventions and most researchers have relied on quantitative measures to assess the impact of interventions on behaviour change. These measures allow researchers to assess outcome related to efficacy and effectiveness of intervention design, but they do not adequately explore the experiences associated with participating in an intervention. In addition, few studies have sufficiently assessed the potential mechanisms of change related to changing health-promoting behaviours [49]. For this reason, it is important to consider study designs that incorporate multiple methods of data collection within experimental studies that collectively aim to understand participants' experiences, evaluate mechanism of change, and assess efficacy and effectiveness of the intervention.

\section{Employ a theory-based approach}

To date, most research with cancer survivors has inconsistently applied theory at various stages of interventions. A theorybased intervention requires consistent application of theory from design to evaluation as it allows for a more in-depth analysis of the impact of the intervention on behaviour change [50]. This is especially of concern for the conduct of telehealth interventions as the necessary components that facilitate change are unclear. Moving forward, it may be valuable to employ one (or more) of the four key theoretical frameworks that have been used to guide intervention design thus far when designing telehealth behaviour change interventions, namely social cognitive, humanistic, dual process, and socioecological [51].

\section{Increase recruitment}

Young adult cancer survivors and rural-living individuals report limited access to research, which may, in part, explain the difficulty associated with recruiting young adult cancer survivors into research trials [71-74]. To facilitate recruitment in a timely-manner, it is critical to utilize alternative strategies to community-based recruitment, including conducting multi-site trials utilizing hospital or clinic staff as champions of research to increase access to the pool of potential participants from which to recruit from. In addition, researchers could consider partnering with healthcare providers, attending hospital rounds to recruit in-person, emailing and/or mailing the study information using tumour registries and/or wellrecognized young adult cancer survivor supportive service providers, and attending cancer-survivorship events/groups [75].

\section{CONCLUSION}

Cancer survivors living in rural communities report engaging in less PA and consuming fewer FVs than their urban counterparts [52], which may place them at an increased 
risk of cancer recurrence, second primary cancer, and noncommunicable chronic diseases [53]. As the number of young adult cancer survivors continues to grow $[41,54]$, it is critical to increase access to behaviour change interventions for this underserved segment of the population. In doing so, it is necessary to explore novel approaches to intervention design to effectively address the needs and preferences of rural-living young adult cancer survivors.

\section{REFERENCES}

1. Statistics., C.C. Physical activity and cancer. 2017; Available from: http:// www.cancer.ca/en/cancer-information/cancer-101/canadian-cancerstatistics-publication/?region=on.

2. Schwedhelm, C., et al., Effect of diet on mortality and cancer recurrence among cancer survivors: A systematic review and meta-analysis of cohort studies. Nutrion Reviews, 2016. 74(12): p. 737-748.

3. Schmid, D., et al., Pre- and post-diagnosis physical activity, television viewing, and mortality among hematologic cancer survivors. PLOS One, 2018. 13(1): p. 1-14.

4. Mishra, S.I., Scherer, R. W., Geigle, P. M., Berlanstein, D. R., Topaloglu, O., Gotay, C. C., \& Snyder, C. , Exercise interventions on health-related quality of life for cancer survivors (Review). Cochrane Database Systematic Review, 2012. 8: p. CD007566.

5. Continuous Update Project Team, W.C.R.F.I., Systematic review on diet, nutrition, physical activity and survival and second cancers in breast cancer survivors. London, UK: World Cancer Research Fund International, 2014.

6. Burnham, T.R., \& Wilcox, A. , Effects of exercise on physiological and psychological variables in cancer survivors. Medicine \& Science in Sports \& Exercise, 2002.

7. Blanchflower, D.G., Oswald, A.J., \& Stewart-Brown, S. , Is psychological well-being linked to the consumption of fruit and vegetables? . Social Indicators Research, 2013. 114(3): p. 785-801.

8. Hill, E., Clinton, S., Grainger, E., Braun, A., Moran, N., Fitz, E., Chitchumroonchokchai, C., Failla, M., \& Spees, C. , Growing Hope: A comprehensive lifestyle intervention increases fruit and vegetable intake and carotenoid status in overweight cancer survivors. Journal of the Academy of Nutrition and Dietetics, 2016. 116(9): p. A82.

9. McMartin, S.E., Jacka, F.N., \& Colman, I. , The association between fruit and vegetable consumption and mental health disorders: Evidence from five waves of a national survey of Canadians. Preventive Medicine, 2013. 56(3): p. 225-230.

10. Schmitz, K.H., et al., American College of Sports Medicine roundtable on exercise guidelines for cancer survivors. Medicine \& Science in Sports \& Exercise,, 2010.42(7): p. 1409-1426.

11. Society, C.C. Physical activity and cancer. 2017; Available from: http://www. cancer.ca/en/prevention-and-screening/live-well/nutrition-andfitness/ physicalactivity/?region=on.

12. Blanchard, C.M., K.S. Courneya, and K. Stein, Cancer survivors' adherence to lifestyle behavior recommendations and associations with healthrelated quality of life: Results from the American cancer society's SCS-II. Journal of Clinical Oncology, 2008. 26(13): p. 2198-2204.

13. Miedema, B., J. Easley, and L. Robinson, Comparing urban and rural young adult cancer survivors' experiences: A qualitative study. Rural and Remote Health, 2013. 13(2324): p. 1-12.

14. Smith, S.A. and B. Ansa, A systematic review of lifestyle interventions for chronic diseases in rural communities. Journal of the Georgia Public Health Association, 2016. 5(4): p. 304-313.

15. Umstattd Meyer, M.R., et al., Rural active living: A call to action. Journal of Public Health Management \& Practice, 2016. 22(5): p. E11-20.

16. James, C.V., et al., Racial/ethnic health disparities among rural adults United States, 2012-2015. Morbidity and Mortality Weekly Report, 2017.
66(23): p. 1-9.

17. Carriere, R., et al., Rural dwellers are less likely to survive cancer - An international review and meta-analysis. Health Place, 2018. 53: p. 219-227.

18. Hastert, T.A., et al., Disparities in cancer incidence and mortality by arealevel socioeconomic status: A multilevel analysis. Journal of Epidemiology and Community Health, 2015. 69(2): p. 168-176.

19. Olson, E.A., et al., Meeting physical activity guidelines in rural breast cancer survivors. American Journal of Health Behavior, 2014. 38(6): p. 890 899.

20. Gray, M.S., et al., Rural-urban differences in health behaviors and outcomes among older, overweight, long-term cancer survivors in the RENEW randomized control trial. Cancer Causes Control, 2019. 30(4): p. 301-309.

21. Byker Shanks, C., et al., Availability, price, and quality of fruits and vegetables in 12 rural montana counties, 2014. Preventing Chronic Disease, 2015. 12: p. E128.

22. de Souza, R.J., et al., Environmental health assessment of communities across Canada: Contextual factors study of the Canadian Alliance for Healthy Hearts and Minds. Cities \& Health, 2018: p. 1-18.

23. Miller, V., et al., Availability, affordability, and consumption of fruits and vegetables in 18 countries across income levels: Findings from the Prospective Urban Rural Epidemiology (PURE) study. The Lancet Global Health, 2016. 4(10): p. e695-e703.

24. Pinard, C.A., et al., An integrative literature review of small food store research across urban and rural communities in the U.S. Prev Med Rep, 2016. 3: p. 324-32.

25. Cleland, V., et al., A qualitative study of environmental factors important for physical activity in rural adults. PLoS One, 2015. 10(11): p. e0140659.

26. Hansen, A.Y., et al., Built environments and active living in rural and remote areas: A review of the literature. Current Obesity Reports, 2015. 4(4): p. 484-493.

27. Cancer, C.P.A., Adolescents \& Young Adults with Cancer: A System Performance Report. 2017, Canadian Partnership Against Cancer: Toronto, ON.

28. Tai, E., et al., Health status of adolescent and young adult cancer survivors. Cancer, 2012. 118(19): p. 4884-91.

29. Epelman, C.L., The adolescent and young adult with cancer: State of the art - psychosocial aspects. Current Oncology Reports, 2013. 15: p. 325-331.

30. D’Agostino, N.M., Penney, A., \& Zebrack, B., Providing developmentally appropriate psychosocial care to adolescent and young adult cancer survivors. Cancer Treatment Reviews, 2011. 117.

31. Berg, C.J., et al., Young adult cancer survivors' experience with cancer treatment and follow-up care and perceptions of barriers to engaging in recommended care. Journal of Cancer Education, 2016. 31(3): p. 430-442.

32. Wu, Y.P., et al., Barriers and facilitators of healthy diet and exercise among adolescent and young adult cancer survivors: Implications for behavioral interventions. Journal of Adolescent and Young Adult Oncology, 2015. 4(4): p. 184-91.

33. Murnane, A., et al., Adolescents and young adult cancer survivors: Exercise habits, quality of life and physical activity preferences. Supportive Care in Cancer, 2015. 23(2): p. 501-10.

34. Ventura, E.E., Ganz, P.A., Bower, J.E., Abascal, L., Petersen, L., Stanton, A.L., \& Crespi, C.M. , Barriers to physical activity and healthy eating in young breast cancer survivors: modifiable risk factors and associations with body mass index. Breast Cancer Research and Treatment, 2013. 142: p. 423-433.

35. Richter, D., et al., Psychosocial interventions for adolescents and young adult cancer patients: A systematic review and meta-analysis. Critical Reviews in Oncology/Hematology, 2015. 95(3): p. 370-86.

36. Pugh, G., et al., The health behaviour information needs and preferences of teenage and young adult cancer survivors. Journal of Adolescent and Young Adult Oncology, 2017. 6(2): p. 318-326.

37. Cox, A., et al., Cancer survivors' experience with telehealth: A systematic review and thematic synthesis. Journal of Medical Internet Research, 2017. 19(1): p. e11.

38. Pugh, G., et al., The lifestyle information and intervention preferences of teenage and young adult cancer survivors: A qualitative study. Cancer 
Nursing, 2018. 41(5): p. 389-398.

39. Nickelson, D.W., Telehealth and the evolving health care system: Strategic opportunities for professional psychology. Professional Psychology: Research and Practice, 1998. 29(6): p. 527-535.

40. Silva, M.N., et al., Using self-determination theory to promote physical activity and weight control: A randomized controlled trial in women. Journal of Behavioural Medicine, 2010. 33: p. 110-122.

41. Zebrack, B. and S. Isaacson, Psychological care of adolescent and young adult patients with cancer and survivors. Journal of Clinical Oncology, 2012. 30(11): p. 1221-1226.

42. DelliFraine, J.L., \& Dansky, K.H. , Home-based telehealth: A review and meta-analysis. Journal of Telemedicine and Telecare, 2008. 14(2): p. 62-66.

43. Davies, C.A., et al., Meta-analysis of internet-delivered interventions to increase physical activity levels. Internation Journal of Behavioural Nutrition and Physical Activity, 2012. 9(52).

44. Webb, T.L., et al., Using the internet to promote behaviour change: A systematic review and meta-analysis of the impact of theoretical basis, use of behaviour change techniques, and mode of delivery on efficacy. Journal of Medical Internet Research, 2010. 12(1): p. e4.

45. Fleig, L., et al., Cross-behaviour associations and multiple health behaviour change: A longitudinal study on physical activity and fruit and vegetable intake. Journal of Health Psychology, 2015. 20(5): p. 525-534.

46. Rabin, C., S. Horowitz, and B. Marcus, Recruiting young adult cancer survivors for behavioral research. Journal of Clinical Psychology in Medical Settings, 2013. 20(1): p. 33-36.

47. Zebrack, B., Bleyer, A., Albritton, K., Medearis, S., \& Tang, J., Assessing the health care needs of adolescent and young adult cancer patients and survivors. Cancer, 2006. 107(12): p. 2915-2923.

48. Pingree, S., et al., The value of theory for enhancing and understanding e-health interventions. American Journal of Preventive Medicine, 2010. 38(1): p. 103-109.

49. Buffart, L.M., et al., Evidence-based physical activity guidelines for cancer survivors: Current guidelines, knowledge gaps, and future research directions. Cancer Treatment Reviews, 2014. 40(2): p. 327-340.

50. Pagato, S. and G.G. Bennett, How behavioural science can advance digital health. Translational Behavioural Medicine, 2013. 3(3): p. 271-276.

51. Rhodes, R.E., D. McEwan, and A.L. Rebar, Theories of physical activity behaviour change: A history and synthesis of approaches. Psychology of Sport and Exercise, 2019. 42: p. 100-109.

52. Rogers, L.Q., et al., Physical activity type and intensity among rural breast cancer survivors: Patterns and associations with fatigue and depressive symptoms. Journal of Cancer Survivorship, 2011. 5(1): p. 54-61.

53. Paskett, E.D., et al., Racial differences in knowledge, attitudes, and cancer screening practices among triracial rural population. Cancer, 2004. 101(11): p. 2650-2659.

54. Epelman, C.L., The adolescent and young adult with cancer: State of the art - psychosocial aspects. Current Oncology Reports, 2013. 15(4): p. 325331. 